\title{
Fontes não codificadas do direito internacional
}

\author{
Eneida Orbage de Britto Taquary
}

\section{RESUMO}

O presente trabalho tem por objetivo o estudo das fontes não codificadas do Direito Internacional. A matéria não encontra uma uniformidade de entendimento em razão de vários fundamentos, dentre eles o fato de que não existe codificação das regras gerais e comuns do Direito Internacional, nem tampouco um sistema normativo hierarquizado, que estabeleça a primazia dos tratados sobre os costumes ou sobre os princípios gerais de direito, a doutrina, a equidade e sobre as normas de caráter peremptório, denominado de jus cogens. No atual cenário internacional, o quadro acima descrito vem sendo alterado em razão do reconhecimento da supremacia dos tratados sobre a ordem interna; o respeito às normas, emanadas de atos de organizações internacionais, que trazem em seu bojo princípios gerais de direito internacional e que têm força cogente e serem aplicadas imediatamente; e por fim o desempenho eficiente da Comissão de direito internacional.

Palavras-Chaves: Fontes de direito internacional; tratados internacionais; organizações internacionais 


\section{INTRODUÇÃO}

O presente trabalho tem por objetivo o estudo das fontes não codificadas do Direito Internacional.

A matéria não encontra uma uniformidade de entendimento em razão de vários fundamentos, dentre eles o fato de que não existe codificação das regras gerais e comuns do Direito Internacional, nem tampouco um sistema normativo hierarquizado, que estabeleça a primazia dos tratados sobre os costumes ou sobre os princípios gerais de direito, a doutrina, a equidade e sobre as normas de caráter peremptório, denominado de jus cogens.

Todavia, o desenvolvimento rápido do Direito Internacional decorreu de sua criação do como ciência autônoma, no século XVII, e das grandes obras de Hugo Grotius (Mare liberum e De jure belli ac pacis), e também devido aos tratados de Vestefália, que difundiu o princípio da igualdade jurídica dos Estados e em conseqüência o do equilíbrio europeu. Foi, porém no século XVIII, por intermédio das primeiras uniões administrativas e a doutrina de Bentham que pregava a codificação como garantia da estabilidade legal da sociedade internacional, que surge pela primeira vez a utilização da expressão internacional law, em 1780.

N o século XI não se pode esquecer de Pasquale Fiore, na Itália, e J. C. Bluntschli, na Suíça, cujos projetos de codificação foram precursores dos trabalhos de codificação interamericano, proposto por José Higino, e realizados no México, que foi coroado com a assinatura em 1928 em Havana da Convenção de Direito Privado, conhecido como Código Bustamante.

A codificação do Direito Internacional também foi preocupação da Liga das Nações que estabeleceu princípios gerais de direitos que deveriam ser seguidos por todos os Países signatários para se alcançar a paz, bem como a criação de uma comissão de peritos encarregada de proceder aos trabalhos de codificação, ensejando a realização da Primeira Conferência de Codificação do Direito Internacional, em Haia, 1930.

Essa preocupação da LdN não foi reforçada na Carta da ONU. Mas, ao dispor sobre a Assembléia Geral, previu no seu art. 13, dentre outras atribuições a de promover do desenvolvimento progressivo do direito internacional e de sua codificação; criou a Comissão e Direito Internacional; e previu por meio do Estatuto da Corte Permanente de Justiça Internacional depois Corte Internacional de Justiça, em seu art. 38 a função de 
decidir de acordo com o direito internacional as controvérsias que lhe forem submetidas, aplicando as convenções internacionais, quer as gerais, quer especiais, que estabeleçam regras expressamente reconhecidas pelos Estados Litigantes; o costume internacional, como prova de uma prática geral aceita como sendo o direito; os princípios gerais de direito, reconhecidos pelas nações civilizadas; sob ressalva da disposição do artigo LIX, as decisões judiciárias e a doutrina dos juristas mais qualificados das diferentes nações, como meio auxiliar para a determinação das regras de direito; e por fim a equidade, ex aequo et bono, desde que as partes com isto concordarem.

Restou provado, com o dispositivo acima que havia a necessidade de estabelecer os meios de produção e elucidação da norma jurídica internacional, sempre que não houvesse o tratado celebrado entre os Estados, ou havendo ocorresse a necessidade de declarar o sentido e o alcance da norma, bem como o interesse da comunidade internacional.

Todavia, com a ONU, o avanço na proclamação de declarações foi desenfreado, dada a necessidade de proteger o homem contra os horrores da Segunda Guerra Mundial e as novas diretrizes da economia mundial, instigando os Estados a aceitarem as resoluções dos organismos internacionais como regras cogentes, e logo como fontes do Direito Internacional.

No campo dos Direitos Humanos as resoluções dos organismos internacionais é indiscutivelmente fonte do direito. Tanto é assim que a nossa Constituição admite nos seus $\S \S 1^{\circ}$ e $2^{\circ}$, do art. $5^{\circ}$, a aplicação imediata das normas definidoras de direitos e garantias fundamentais, entendendo essas como as constantes na Constituição Federal, decorrentes dos princípios por ela adotados ou dos tratados internacionais em que o Brasil seja parte. O mesmo se pode afirmar quanto à matéria tributária, porque o nosso Código Tributário Nacional estabelece em seu art. $98^{1}$, que os tratados de direito tributário têm supremacia sobre a lei nacional.

Todavia, a aplicação imediata de resoluções de organismos internacionais e dos próprios tratados em outras áreas do direito que não versem sobre direitos humanos e tributário segue procedimento totalmente diverso quanto ao seu reconhecimento e sua aplicação. Deve anteriormente à sua entrada em vigor, ser aprovado pelo Congresso 
Nacional, por intermédio de Decreto Legislativo e posteriormente ratificado por ato do Presidente da República.

Logo, com a estrutura constitucional em vigor, ainda que o Brasil reconheça as fontes do direito internacional não codificadas, se essas não forem, por intermédio de tratados, convalidados pelos Poderes Legislativo e Executivo, não terão força cogente e logo poder de coerção, de se fazerem valer.

No atual cenário internacional, o quadro acima descrito vem sendo alterado em razão do reconhecimento da supremacia dos tratados sobre a ordem interna; o respeito às normas, emanadas de atos de organizações internacionais, que trazem em seu bojo princípios gerais de direito internacional e que têm força cogente e serem aplicadas imediatamente; e por fim o desempenho eficiente da Comissão de direito internacional.

Entretanto ainda hoje as fontes do Direito Internacional são divididas em formais e materiais, convencionais ou não, codificadas ou não codificadas. As chamadas fontes materiais, reais, direitas ou mediatas retratam os elementos fáticos decorrentes da dados históricos, sócio-econômicos, culturais, geográficos e políticos, vigorantes em determinadas épocas e que conduzem à elaboração de uma norma aceita pelos Estados ou de um tratado internacional. Estas integram as chamadas não escritas, convencionais ou não convencionais.

Dentre as fontes materiais convencionais não escritas estão incluídos os costumes, os princípios gerais de direito, a equidade, a doutrina, e a jurisprudência dos publicistas, mais qualificados. São estas as fontes mencionadas no art. 38 do Estatuto do Tribunal Internacional de Justiça. As fontes materiais não codificadas ou não convencionais são expressas por meio dos atos de organizações internacionais, os atos unilaterais dos Estados e o jus cogens. Essas últimas integram o objeto do nosso trabalho.

\footnotetext{
${ }^{1}$ O art. 98 do Código Tributário Nacional dispõe: “ Os tratados e as convenções internacionais revogam ou modificam a legislação tributária interna, e serão observados pela que lhes sobrevenha.
} 


\section{FONTES DO DIREITO INTERNACIONAL}

\subsection{GENERALIDADES}

A dificuldade em tratar do tema fontes do Direito Internacional está relacionada com a ausência de um sistema legislativo internacional, que apesar de ser anseio da Comunidade Internacional, vem se constituindo de forma lenta, caracterizando-se por intermédio das regras da Comissão do Direito Internacional, órgão auxiliar da ONU, criado em 1947, com função específica de incentivar o desenvolvimento progressivo do Direito Internacional e sua codificação; e pela celebração de tratados, cujo processo de elaboração foi estabelecido na Convenção de Viena Sobre Direito Dos Tratados, datada de 1969, ainda não ratificado pelo Brasil.

O objetivo de codificação do Direito Internacional, transformando todas as regras em escritas, sistematizando-as e classificando-as, apesar de ter sido incrementado no século passado, teve sua gênese no século XVIII, com Bentham, que pregava a codificação como garantia da estabilidade legal da sociedade internacional ${ }^{2} .2$ Mas, o início da efetivação dessa sistematização teve sua expressão com a Paz de Westfália, datada de 1648, que marcou o término da Guerra dos Trinta Anos, e a primeira iniciativa dos Estados Europeus deliberarem em conjunto. Após a Revolução francesa e sua influência benéfica, vieram as primeiras uniões administrativas e o Congresso de Viena sobre o Danúbio e o Reno $^{3}$, datado de 1814-1815, regulando a navegação, bem como outras convenções abolindo o comércio de escravos.

Na evolução da codificação do Direito Internacional há que se mencionar a criação do congress system, que viabilizou a celebração de muitos tratados em congressos ou conferências internacionais; da Internacional Law Association, Institut de Droit Internacional ( 1873), e o Harvard Research in International Law (1927); as Conferências da Haia, de 1899 e $1907^{4}$, a criação do commitee of experts for the progressive codification

\footnotetext{
${ }^{2}$ Jo, Hee Moon. Introdução ao Direito Internacional, ed. LTr.. 5aed., São Paulo.2000. p. 154.

${ }^{3} \mathrm{O}$ congresso de Viena foi significativo porque além da internacionalização dos rios, houve a proibição do tráfico de negros, bem como a criação de novos países e classificação de agentes diplomáticos.

${ }^{4}$ A primeira conferência criou a Corte Permanente de Arbitragem e deu conclusão à Convenção sobre a guerra terrestre e marítima, bem como a proibição do uso de determinados explosivos e gases durante a
} 
of international law pela Sociedade das Nações até a Carta da Organização das Nações Unidas, que promoveu a criação da International Law Commission, atendendo aos objetivos propugnados em seu art. $13^{5}$.

Não se pode deixar de mencionar as seguintes conferências que tinham por objetivo a codificação do direito internacional público:

1. Conferência de Genebra sobre o direito do Mar-1948. Tratou da largura do mar territorial, pesca e conservação dos recursos biológicos do mar, acesso ao mar de países sem litoral e a plataforma continental. Além dessa uma outra ocorreu em 1958, não fixando ainda a largura do Mar territorial e outras quatro sobre o mar territorial; o Alto mar; Plataforma Continental e Conservação dos Recursos vivos do Mar.

2. Conferência de Viena sobre Relações Diplomáticas-1961. Destacou-se pela liberalidade com que tratou os detentores de prerrogativas e imunidades diplomáticas. Tratou ainda da utilização de aparelhos radiofônicos. O agente diplomático deixa de ser um para compreender a Missão.

3. Conferência de Viena sobre Relações Consulares-1963. Tratou das atribuições consulares, o fazendo de forma exemplificativa e não exaustiva. Também previu alguns privilégios e imunidades aos cônsules honorários semelhantes aos cônsules de carreira.

4. Convenção sobre Missões Diplomáticas-1969. A Comissão de Direito Internacional ao concluir que ao lado da diplomacia tradicional havia a diplomacia ad hoc, referente à enviados itinerantes, à conferências diplomáticas e missões especiais elaborou uma minuta da Convenção sobre Missões Diplomáticas que não foi submetida à Conferência, mas à AGNU em 08.12.69, que denominou missão especial como “ uma missão temporária, representando o Estado, enviada por um Estado a outro Estado com o

guerra. Já a Segunda, além de estabelecer a regulamentação pacífica dos conflitos mundiais instituiu uma Corte Internacional de Presas, onde enumerou as fontes a serem aplicadas pelas cortes, como sendo os tratados e as regras gerais internacionais e, na falta destes, a justiça e a equidade.

${ }^{5} \mathrm{O}$ art. 13 da Carta das Nações Unidas estabelece que a Assembléia Geral promoverá estudos e fará recomendações, tendo em vista: fomentar a cooperação internacional no plano político e incentivar o desenvolvimento progressivo do direito internacional e a sua codificação; e fomentar a cooperação internacional no domínio econômico, social, cultural, educacional e da saúde e favorecer o pleno gozo dos direitos do homem e das liberdades fundamentais, por parte de todos os povos, sem distinção de raça, sexo, língua ou religião. 
consentimento deste com o objetivo de tratar de questões específicas ou de executar com a mesma uma função específica ${ }^{6}$.

5. Convenção sobre Relações entre Estados e Organizações Internacionais1982. Originou-se de discussões acerca das relações diplomáticas. Apesar de escolhido um relator especial em 1959, somente em 1971 a Comissão de Direito Internacional elaborou uma minuta que versava sobre Missões junto à organizações internacionais e Delegações enviadas a órgãos ou a conferências, sem que fossem adotadas, motivando sua nova apreciação na Conferência de Viena de 1975. Estabeleceu o direito de um Estado declarar um delegado pessoa non grata; reconheceu a inviolabilidade da residência particular do Chefe da Delegação e demais funcionários diplomáticos e de seus bens; excluiu do âmbito da Convenção as organizações de caráter regional. Dada a divergência da matéria a convenção não entrou em vigor.

6. Conferência de Viena Sobre a Sucessão De Estados- 1977 e 1978 (primeira) e 1983 ( segunda). Ambas foram rejeitadas porque não houve número de ratificações suficientes. Tinha por objeto a análise da transferência de parte do Estado, sem que houvesse a extinção de um deles; união de Estados; surgimento de um novo Estado que tenha declarado independência; dissolução de um Estado para formação de outros e a dissolução de um Estado.

7. Conferência sobre Direito dos Tratados de Organizações InternacionaisDenominada de Convenção de Viena II, foi assinada em 21.03.86, disciplinando o direito de tratados entre Estados e Organismos Internacionais ou entre Organizações Internacionais. O estudo do direito dos tratados e organizações internacionais foi iniciado em 1950, mas somente em 1971, quando Paul Reuter foi escolhido relator especial e apresentou vários relatórios teve seu avanço. Todavia em razão de problemas de várias ordens, inclusive financeiros, a AGNU decidiu que somente os artigos polêmicos seriam discutidos, os demais seriam apenas revisados. Dentre os dispositivos polêmicos deve ser ressaltado o que estabelecia a capacidade das organizações internacionais em firmar tratados.

8. Convenção sobre o Direito do Mar oi assinada em 1982, em Montego Bay, após onze anos de reuniões de delegados em vários países. Restringiu-se a disciplinar a

\footnotetext{
${ }^{6}$ G. E. do Nascimento e Silva e Hildebrando Acciolly. Manual de Direito Internacional Público.
} 
matéria segundo a Convenção de 1958 sobre Mar Territorial e Alto Mar. Em 1970, em razão das declarações sobre as riquezas minerais e sua exploração nos mares, de Arvid Pardo na Terceira Conferência Sobre o Direito Do Mar, foi aprovada a resolução que declarou a área patrimônio comum da humanidade. Teve por objeto três matérias: “a exploração do fundo dos mares e seu subsolo, a extensão dos limites marítimos dos Estados Costeiros e a determinação dos direitos dos Estados sem litoral marítimo e os dos Estados geograficamente desfavorecidos”7.

Convenções sobre assuntos científicos e tecnológicos e sobre o meio ambienteessas convenções foram realizadas visando adequar o direito internacional às mudanças no campo científico e tecnológico, bem como às necessidade de atender à preservação do meio ambiente. Note-se que após a Segunda Guerra Mundial as preocupações dos Estados giravam em torno do espaço aéreo, mar e terra. Era tridimensional ${ }^{8}$. Vários tratados foram celebrados. Dentre eles destacamos: Tratado da Antártida (1959); Tratado Sobre Princípios Reguladores das Atividades dos Estados na Exploração e Uso do Espaço Cósmico, inclusive Lua e demais Corpos Celestes (1967); Tratado Proibindo Experiências (testes) com Armas Nucleares na Atmosfera, no Espaço Cósmico e Debaixo D’água (1963); Tratado Sobre a Proibição da Colocação de Armas Nucleares e outras Armas de Destruição Maciça no Fundo do Mar e no Leito do Oceano e seu Subsolo (1971).

Além dessas outras mais recentes foram realizadas visando à proteção do meio ambiente, ressaltando: Convenção Sobre as Zonas Úmidas De Importância internacional particularmente como Habitat das Aves Aquáticas (1971); Convenção para a Prevenção da Poluição Marinha pelo Alijamento de Dejetos e outra Matérias (1972); Convenção Sobre O Comércio Internacional das Espécies da Flora e da Fauna Selvagens em Perigo de Extinção(1973); Tratado de Cooperação Amazônica (1978); Convenção de Viena Sobre a Proteção da Camada de Ozônio (1985); Protocolo de Montreal Sobre Substâncias que destroem a Camada de Ozônio (1987); Convenção de Basiléia sobre o Controle de Movimentos Transfronteiriços de Resíduos Nocivos e sua Colocação (1989); Convenção Sobre Mudança de Clima e Sobre Diversidade Biológica (1992).

\footnotetext{
7 G. E. do Nascimento e Silva e Hildebrando Acciolly. Manual de Direito Internacional Público, p. 59.

${ }^{8}$ Denominação utilizada por G. E. do Nascimento e Silva e Hildebrando Acciolly, em Manual de Direito Internacional Público. p. 60.
} 
Não se pode deixar de mencionar nesse contexto a Declaração de Princípios com Autoridade não Juridicamente Obrigatória para um Consenso Global Sobre Manejo, Conservação e Desenvolvimento Sustentável de Todos os Tipos de Florestas e a Convenção Climática de Kioto, que tinha por objeto firmar um protocolo onde os Estados se obrigassem a reduzir em $60 \%$ (sessenta por cento) a emissão de gases poluentes, em decorrência de estudos levados a efeito pela PICC, organismo da ONU criado para estudar o Clima, em razão de catástrofes que vêm ocorrendo em todo o mundo. Infelizmente, os Estados Unidos retirou-se da Convenção e pressionou os outros Estados para que as negociações fossem proteladas, restando apenas o estabelecimento de um percentual a que os Estados se obrigaram bem inferior ao inicialmente indicado como necessário.

\subsection{CONCEITO E TERMINOLOGIA}

O termo fontes do Direito Internacional não diversamente da denominação genérica de fontes do Direito é metaforicamente usada para designar os meios de formação ou cognição da norma. Eles são os responsáveis pelo nascimento da norma ou pelo conhecimento de seu conteúdo9 .

No âmbito do direito interno o processo legislativo, bem como o sistema de elaboração da norma, fonte primeira do direito, é especificado na Constituição Federal, estabelecendo o Poder competente e os seus órgãos, bem como a hierarquia das normas. Caracteriza-se como centralizado e verticalizado, porque não é qualquer órgão que pode elaborar a norma e ela é hierarquizada, de forma de uma possui maior valor sobre outras. Inversamente é o sistema de elaboração da norma internacional, se é que se pode falar em sistema, porque não existe, como visto acima, um órgão nuclear encarregado dessa função de criar a fonte imediata- a norma internacional, e que ainda estabeleça a hierarquia desses meios de produção. É, pois, descentralizado e horizontalizado, na medida em que os

\footnotetext{
${ }^{9}$ Segundo Norberto Bobbio, em sua obra O Positivismo Jurídico, p.161, fontes do direito são aqueles fatos ou aqueles atos aos quais um determinado ordenamento jurídico atribui a competência ou a capacidade de produzir normas jurídicas. (Falamos de fatos ou de atos em relação aos quais se prescinde da consideração do elemento subjetivo- conhecimento e vontade- próprio do agir do ser humano, ou são comportamentos humanos que abrangem tal elemento subjetivo; com referência aos fatos falamos de competência, com referência aos fatos falamos de capacidade).
} 
Estados são os sujeitos responsáveis pela elaboração dos vários meios de produção das regras internacionais.

O ordenamento jurídico pode ainda segundo a ótica de Noberto Bobbio ser paritário, pois “existem várias fontes colocadas no mesmo plano, o que significa, sem metáfora, várias normas que têm o mesmo valor; e de hierárquico ou hierarquizado o ordenamento no qual há várias fontes não colocadas no mesmo plano, mas colocadas em planos diferentes, isto é, não têm o mesmo valor, mas sim um valor diferente, maior ou menor, visto que estão hierarquicamente subordinadas uma à outra” ${ }^{\text {10 }}$. Diferencia ainda os sistemas em simples e complexos, segundo possuam uma única fonte ou várias fontes, sempre hierarquizadas, admitindo que historicamente a investigação sobre os sistemas jurídicos nos conduziria sempre a um sistema complexo.

O direito internacional não excepciona a regra extraída da análise dos vários ordenamentos que vigeram ou vigem. Em sua totalidade são sistemas complexos que não possuem apenas o tratado como fonte imediata, mas outras como os costumes, a doutrina, os princípios gerais de direito e a equidade.

É necessário que se esclareça que as normas internacionais surgiram a partir do momento que os Estados entenderam que podiam unir suas vontades, para criar uma Sociedade Internacional. Daí decorre que não se pode desprezar os atos de manifestação de vontade dos organismos internacionais, nem tampouco dos Estados que a eles aderem.

Todavia, o tema tem sido tratado de forma errônea e incompleta pelos doutrinadores. Errônea porque alguns confundem fonte com fundamento, isto é a sua formação com a sua validade. Incompleta porque se apegam às fontes elencadas pela ONU, por intermédio do Estatuto da Corte Internacional de Justiça ${ }^{11}$, que de forma enunciativa as prevê. São elas:

a) as convenções internacionais- gerais ou especiais;

\footnotetext{
${ }^{10}$ BOBBIO, Norberto. O Positivismo Jurídico. São Paulo: Ícone, 1995. p. 162.

11 O art. 38 da Corte Internacional de Justiça dispõe: “ 1) A Corte, cuja função é decidir de acordo com o direito internacional as controvérsias que lhe forem submetidas, aplicará: a) as convenções internacionais, quer as gerais, quer especiais, que estabeleçam regras expressamente reconhecidas pelos Estados Litigantes; b) o costume internacional, como prova de uma prática geral aceita como sendo o direito; c) os princípios gerais de direito, reconhecidos pelas nações civilizadas; d) sob ressalva da disposição do artigo LIX, as decisões judiciárias e a doutrina dos juristas mais qualificados das diferentes nações, como meio auxiliar para a determinação das regras de direito.

2) A presente disposição não prejudicará a faculdade da Corte de decidir uma questão ex aequo et bono, se as partes com isto concordarem.”
} 
b) o costume internacional;

c) os princípios gerais de direito;

d) a doutrina dos publicistas mais qualificados e suas decisões judiciárias, como meios auxiliares;

e) a equidade (ex aequo bono)".

Da enumeração das fontes pelo Estatuto da Corte Internacional de Justiça várias conclusões são extraídas: 1. não é uma enumeração taxativa, mas enunciativa, não havendo entre elas uma hierarquia, o que se justifica porque o rol dessas fontes foi estabelecido no Estatuto da Corte Permanente de Justiça Internacional e posteriormente aproveitado no da Corte Internacional de Justiça; em decorrência da dissolução da Sociedade das Nações e o surgimento da ONU; 2. as fontes principais são os tratados e os costumes e as secundárias são os princípios gerais de direito, a doutrina dos publicistas mais qualificados e suas decisões judiciárias, como meios auxiliares e a equidade (ex aequo bono); 3.a finalidade desse dispositivo é estabelecer a norma a ser aplicada em uma controvérsia que lhe foi submetida voluntariamente pelos Estados. Seja pelo tratado, ou não havendo, pela equidade se assim as partes anuírem; 4. a totalidade dos países é parte da ONU e por força dos seus arts. 35 e $93.2^{12}$ aceitam a Corte Internacional de Justiça como órgão judicial; e, 5. as fontes enumeradas desprezam os atos unilaterais dos Estados e os atos dos órgãos internacionais com conteúdo normativo.

Não se pode olvidar que a única fonte codificada e que tem supremacia sobre as demais é o tratado, desde que não sejam contrárias às normas peremptórias de direito internacional (jus cogens), o que nos leva a afirmar que existe uma correlação estreita entre a formação do direito com a sua força obrigatória e a validade com a sua força executória.

A força obrigatória é expressa pela característica intrínseca e inerente ao direito, inclusive ao direito internacional, que é a coerção, que o torna obrigatório. A coação somente vem à tona para garantir a validade das decisões emanadas das Instituições. Daí

\footnotetext{
${ }^{12}$ O Art. 35 da Carta da ONU dispõe que “ 1. qualquer membro das Nações Unidas poderá chamar a atenção do Conselho de Segurança ou da Assembléia Geral para qualquer controvérsia ou qualquer situação da natureza das que se acham previstas no art. 14; 2.Um Estado que não seja membro das Nações Unidas poderá chamar a atenção do Conselho de Segurança ou da Assembléia Geral para qualquer controvérsia em que seja parte, uma vez que aceite previamente, em relação a essa controvérsia, as obrigações de solução pacífica previstas na presente Carta (...)." e o seu art. 93.2. preceitua: "Um Estado que não seja membro das Nações Unidas poderá tornar-se parte no Estatuto do Tribunal Internacional de Justiça, em condições que serão determinadas, em cada caso, pela Assembléia Geral, mediante recomendação do Conselho de Segurança.”
} 
porque não se pode afirmar que o Direito Internacional não possui força obrigatória porque não tem mecanismos de coação material. Esse pensamento não é correto se levamos em conta que a coercibilidade, característica do direito, inerente à sua essência, porque é seu elemento constitutivo, porém abstrato, que mesmo sendo violado continua a existir, enquanto a coação, somente excepcionalmente terá lugar, em razão de dois fatores: a negação da coercibilidade e mecanismos de legitimados pela ordem jurídica para o restabelecimento da manutenção e garantia das instituições jurídicas.

Logo ao se falar em fontes do direito internacional, referimo-nos à sua formação, e logo, à sua força obrigatória, a sua coercibilidade. A coação, o constrangimento ao cumprimento das normas de direito internacional (tratados, costumes, decisões judiciárias, e outras), apesar de legitimada normativamente, in genere,, se refere ä sua força executória. Portanto, força obrigatória e coercibilidade todas as normas do direito internacional terão, independentemente de sua fonte de produção, todavia, assim como qualquer norma jurídica, poderá ter força executória, segundo haja a previsão de instrumentos que constranjam os Estados à reparara quebra do princípio ínsito na norma. Certamente, não se pode desprezar o fato de que a coação se agrega à coerção da norma para lhe dar eficácia.

Estabelecida a distinção entre coação e coerção, passaremos a tratar dos meios de formação das normas de Direito Internacional.

\subsection{CLASSIFICAÇÃO}

As fontes do Direito Internacional como meios de explicitação e de sua formação não podem ser reduzidas aos chamados "meios formais”, ou fontes formais, que expressam as regras jurídicas, que são chamadas de imediatas ou direitas, porque em geral são escritas, positivadas por intermédio de celebração de tratados. Nesse particular, não se deve incluir a lei interna, ainda que assimile totalmente o conteúdo do tratado, seja elaborando norma ordinária ou aplicando o conteúdo deste por decisões judiciárias.

Apesar de denominarem-se fontes formais, somente o tratado integra essa classificação, pois é o único meio escrito e codificado de formação do Direito Internacional, em que pese a maioria dos autores incluir os costumes e princípios gerais de 
direito nesse rol de classificação, porque acabam por confundir fontes formais com fontes convencionais. Estas são todas aquelas já mencionadas e que compõem o rol do art. 38 da Corte Internacional de Justiça. São chamadas de convencionais porque aceitas pela Comunidade Internacional, sejam escritas ou não.

As chamadas fontes materiais, reais, direitas ou mediatas retratam os elementos fáticos decorrentes da dados históricos, sócio-econômicos, culturais, geográficos e políticos, vigorantes em determinadas épocas e que conduzem à elaboração de uma norma aceita pelos Estados ou de um tratado internacional. Estas integram as chamadas não escritas, convencionais ou não convencionais.

Dentre as materiais convencionais não escritas estão incluídos os costumes, os princípios gerais de direito, a equidade, a doutrina, e a jurisprudência dos publicistas, mais qualificados. São estas as fontes mencionadas no art. 38 do Estatuto do Tribunal Internacional de Justiça.

As fontes materiais não codificadas eu não convencionais são expressas por meio dos atos de organizações internacionais, os atos unilaterais dos Estados e o jus cogens.

Alguns autores mencionam ainda a classificação das fontes do direito internacional segundo sua força vinculativa em hard law e soft law. As primeiras também chamadas de direito “duro” são as que possuem força vinculativa, enquanto as segundas são as chamadas de direito mole e logo sem força obrigatória. Entre as primeiras encontramos as Convenções internacionais, os princípios gerais de direito, as decisões judiciárias e as doutrinas, os atos unilaterais e as decisões normativas das Organizações Internacionais. Já entre as soft law encontramos as resoluções ou declarações das Organizações Internacionais, acordos sem força vinculativa, estatuto e diretrizes.

Todavia não se pode olvidar que na forma prevista não art. 38 da Corte internacional de Justiça, as fontes do Direito Internacional são classificadas:

a) fontes formais: os tratados e os costumes internacionais;

b) fontes materiais: a equidade, os princípios gerais de direito, as decisões judiciais e a doutrina dos publicistas mais qualificados e a analogia;

c) fonte codificada: os tratados;

d) fontes não codificadas: os costumes internacionais; atos de organizações internacionais, os atos unilaterais dos Estados e o jus cogens. 
e) fontes convencionais: os tratados; os costumes internacionais; a equidade, os princípios gerais de direito, as decisões judiciais e a doutrina dos publicistas mais qualificados e a analogia;

f) fontes auxiliares: as decisões judiciárias e a doutrina dos juristas mais qualificados das diferentes nações, como meio auxiliar para a determinação das regras de direito.

A classificação das fontes do Direito Internacional em formais, materiais, convencionais, não convencionais, codificadas ou não, nos leva a estabelecer, para efeito de apreciação no presente trabalho, a seguinte classificação, conforme quadro abaixo. A única fonte codificada é o tratado e as não codificadas são os costumes internacionais, os atos de organizações internacionais, os atos unilaterais dos Estados e o jus cogens, sendo a primeira convencional e as demais não convencionais .

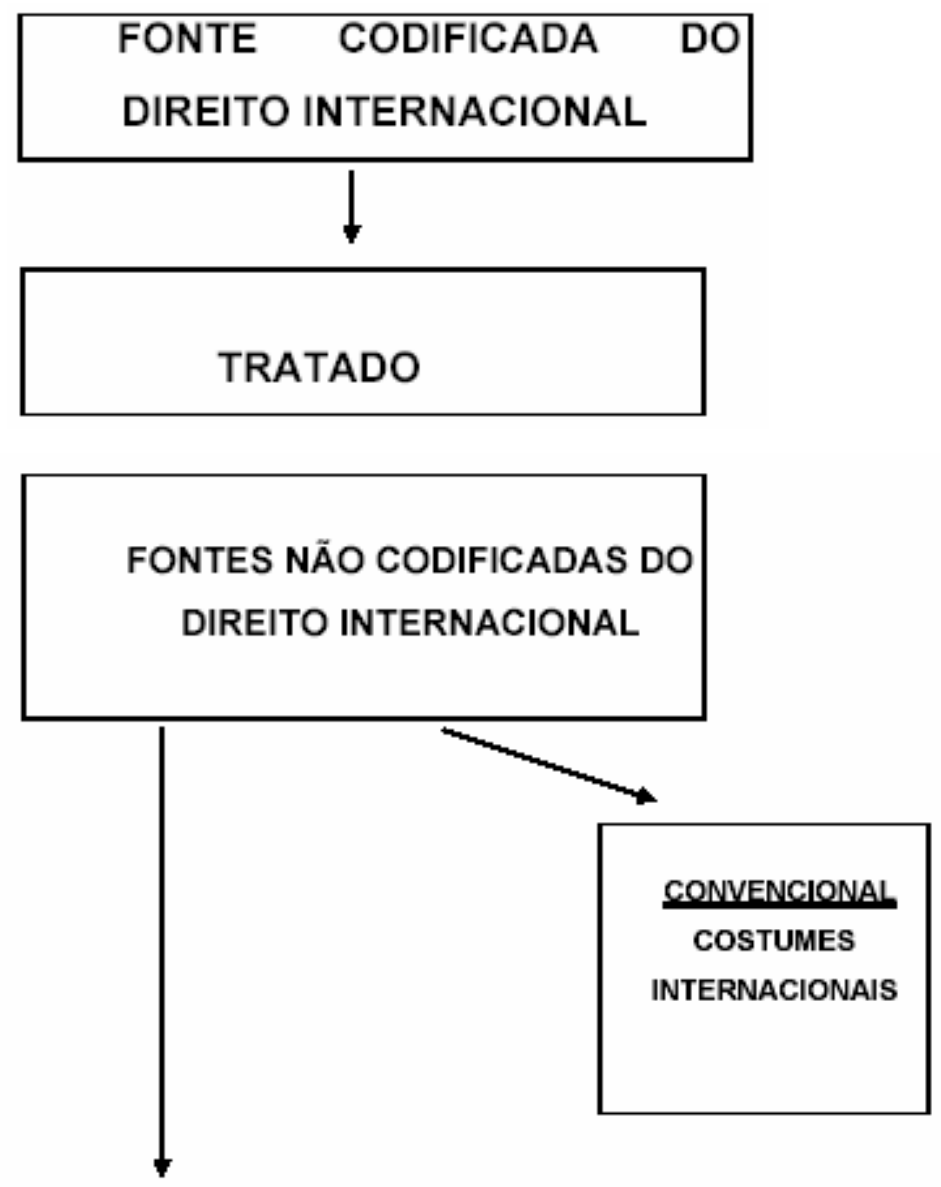

NÅO CONVENCIONAIS

OS ATOS DE ORGANIZAÇÖES INTERNACIONAIS

OS ATOS UNILATERAIS DOS ESTADOS 


\section{FONTES NÃO-CODIFICADAS DO DIREITO INTERNACIONAL}

\subsection{NOÇÕES INTRODUTÓRIAS}

A fonte não codificada do Direito Internacional antes da Segunda Guerra Mundial consistia em especial pelo costume internacional que se consolidava no decorrer de longos anos. Todavia com o aparecimento de vários Estados que não coadunavam com a regra costumeira e com o aparecimento de problemas que afligiam a Comunidade Internacional foi necessário que a disciplina da matéria controversa fosse rapidamente estabelecida, motivando o surgimento de muitos tratados, inclusive de Convenção que dele tratasse.

Certamente como fonte convencional não codificada o costume reina, mas quando se tratam das não codificadas e não convencionais é necessário mencionar os atos unilaterais das Organizações internacionais; atos unilaterais dos Estados e o jus cogens. Essas três fontes prioritárias ganharam força, devido à necessidade dos Estados comporem organismos internacionais para resolução de seus problemas, para o fortalecimento de medidas de cooperação e proteção para manutenção da paz, mas principalmente porque há vontade da Sociedade Internacional em codificar as suas normas, constituindo um sistema hierarquizado. Deve-se mencionar ainda que a ONU por intermédio de suas comissões vêm realizando estudos em várias áreas e emitindo resoluções, declarações e recomendações aos Estados disciplinando-as.

Em âmbito de direitos humanos a força desses atos unilaterais das Organizações internacionais é marcante porque além de estabelecerem direitos e deveres de todos os homens, prevêem formas de monitoramento e tutela desses direitos, aos quais os Estados estão submetidos, voluntariamente, aceitando uma intervenção em seu domínio e conseqüentemente aceitando a reformulação do conceito tradicional de soberania.

Exemplo recente e significativo dessa força cogente dos atos de organizações internacionais é a adesão do Brasil à Convenção Americana de Direitos Humanos ou Pacto de São José da Costa Rica, bem como a sua denominada cláusula facultativa que sendo ratificada pelo Estado-Parte o sujeita à decisões da Corte Interamericana de Direitos 
Humanos, possuindo essas força executiva. Outros exemplos Clássicos, mais distantes no tempo, porém deveras representativos são as Declarações.

O Brasil adotou a Declaração Americana dos Direitos e Deveres do Homem, a Carta Internacional Americana de Garantias Sociais, e a Declaração Universal dos Direitos do Homem. Também ratificou: a) a Convenção Interamericana para Prevenir e Punir a Tortura, em 20 de julho de 1989; b) a Convenção sobre os Direitos da Criança, em 24 de setembro de 1990; c) o Pacto Internacional dos Direitos Civis e Políticos, em 24 de janeiro de 1992; d) o Pacto Internacional dos Direitos Econômicos, Sociais e Culturais, em 24 de janeiro de 1992; e) a Convenção Americana de Direitos Humanos, de 25 de setembro de 1992; f) a Convenção Interamericana para Prevenir, Punir e Erradicar a Violência contra a Mulher, em 27 de novembro de 1995.

Atualmente a tendência de codificar-se o Direito Internacional tem sido impulsionada não só pelo grande número de tratados que foram e estão sendo celebrados, mas também pela necessidade de se estabelecer regras internacionais que sejam respeitadas e cumpridas por todos os Estados, de forma célere e consensual .

\subsection{ATOS DAS ORGANIZAÇÕES INTERNACIONAIS}

Apesar de não constar da enumeração exemplificativa do Estatuto da Corte Internacional de Justiça, art. 38, como fonte do Direito Internacional, é incontestável que os atos das organizações internacionais fazem nascer a norma jurídica internacional.

Essa posição se ao término das duas Guerras Mundiais não estava sedimentada, passou a consolidar-se expressamente com a Carta da ONU, que em seu preâmbulo estabelece a necessidade de preservar as gerações vindouras do flagelo da guerra que trouxe grandes sofrimentos à humanidade; a reafirmação dos direitos fundamentais do homem, na dignidade e no valor da pessoa humana; mas também e principalmente estabelecer condições necessárias à manutenção da justiça e do respeito das obrigações decorrentes de tratados e de outras fontes do direito internacional. Para a consecução de tais objetivos a Carta da ONU instituiu vários órgãos que a compõem: Assembléia Geral, Conselho de Segurança, Conselho de Economia Social, Conselho Tutelar, Organização Internacional do 
Trabalho e Corte Internacional de Justiça. Todos esses órgãos segundo o art 7, item 2, da Carta, poderão criar os órgãos subsidiários necessários a concretização de seus fins.

A Assembléia Geral promoverá estudos e fará recomendações visando a cooperação internacional no plano político e o incentivo o desenvolvimento progressivo e à codificação do direito internacional, por intermédio de órgãos subsidiários que poderá $\operatorname{criar}^{13}$.

Também o Conselho de Segurança deve instituir os órgãos necessários ao desempenho de suas atribuições, bem como elaborar recomendações sobre procedimentos ou métodos aos Estados para solução de suas controvérsias ${ }^{14}$.

Nessa mesma linha a Carta da ONU estabelece a previsão de celebração de acordos internacionais e de instituição de organismos internacionais para a manutenção da paz e segurança internacionais, desde que respeitados os princípios e objetivos das Nações Unidas $^{15}$. Devendo ressaltar o Conselho Econômico e Social (ECOSOC) que possui como uma de suas funções a promoção e observância dos direitos do homem e das liberdades fundamentais, sendo o principal órgão da ONU que defende os interesses do homem. Coube a esse, a apresentação à Assembléia Geral da Declaração Universal dos Direitos do Homem, que a aprovou em 10 de dezembro de 1948 e que foi aceita pela maioria absoluta dos países.

Há que se mencionar ainda que o Conselho Econômico e Social (ECOSOC) poderá enviar recomendações à Assembléia Geral, aos membros da ONU e aos organismos internacionais, bem como convocar conferências e elaborar minutas de convenções ${ }^{16}$.

Os exemplos dados seriam infindáveis em razão do número de organismos internacionais que foram criados, com funções diversas, em razão dos movimento de globalização da economia e da absorção pelos Estados de um novo conceito de soberania e de sujeito de direito internacional, de forma a admitir a inserção na ordem interna de normas internacionais de direitos humanos, como a submissão à decisões de Cortes Internacionais de Direitos Humanos, com força executiva; normas trabalhistas da Organização Internacional do Trabalho e mais recentemente a Lei Modelo sobre Comércio

\footnotetext{
${ }^{13}$ Arts. 13 e 22 da Carta da ONU.

${ }^{14}$ Arts. 29, 33 e segs. da Carta da ONU.

${ }^{15}$ Art. 44 da Carta da ONU.

${ }^{16}$ Art. 62 da Carta da ONU.
} 
Eletrônico elaborada pela Comissão das Nações Unidas para o Direito Comercial Internacional ( UNCITRAL); a Convenção Climática de Kioto; e a Conferência das Nações Unidas contra o Racismo, a Discriminação Racial, a Xenofobia e a Intolerância, conhecida como Conferência de Durban.

A problematização do tema entretanto recai sobre a natureza jurídica dos atos praticados pelos organismos internacionais, se produzem conseqüências, criando direitos e impondo obrigações aos Estados. Os atos das organizações internacionais são oriundos de suas atribuiç̧̃̃es constantes nos seus estatutos que as constituem, motivo pelo qual já houve reconhecimento, da Corte Internacional de Justiça, de que os estatutos jurídicos das organizações internacionais têm validade jurídica e são utilizados nos pareceres e nas decisões como fundamento.

Ao lado dos estatutos dos organismos internacionais, deve ser realçado os atos jurídicos por eles praticados e que podem produzir conseqüências jurídicas.

Quando emanam de órgão colegiado são denominadas de resoluções. As de caráter obrigatório são denominadas de decisões. E as de caráter facultativo são as recomendações. As primeiras obrigam a todos os Estados indistintamente como ato do Conselho de Segurança da $\mathrm{ONU}^{17}$. Criam direitos e obrigações na esfera jurídica internacional; enquanto as segundas, apenas advertem, aconselham ou convidam os Estados-membros; Estados não membros, organizações internacionais e órgãos internos da própria organização internacional a adotar um determinado comportamento, ou estabelecem instruções para os organismos subordinados. São emanadas da Assembléia Geral da $\mathrm{ONU}^{18}$, por intermédio de seus órgãos subsidiários.

Não se pode olvidar do valor jurídico das recomendações quando avaliamos as conseqüências das Cartas, Declarações, Convenções, Conferências e demais documentos que contenham em seu bojo os princípios universalmente aceitos pelas nações, baseados na dignidade e no valor da pessoa humana, na igualdade de direitos das nações, bem como no progresso social e em melhores condições de vida dentro de um conceito mais amplo de liberdade $^{19}$, que ensejam a criação de normas jurídicas.

\footnotetext{
17 Art. 25 da Carta da ONU.

${ }^{18}$ Arts. 10 e 11 da Carta da ONU.

${ }^{19}$ Preâmbulo da Carta da ONU.
} 
Como exemplos de casos concretos de criação de normas jurídicas por meio dos atos de organismos internacionais podemos citar os regulamentos sanitários da Organização Mundial da Saúde; as recomendações da Organização Internacional do Trabalho, em que o Estado está obrigado a informar as medidas que foram adotadas para a proteção do trabalho e a situação do direito interno no tocante ao objeto de determinada conferência; a Carta Internacional de Direitos Humanos que contém a Declaração Universal dos Direitos Humanos; e os Pactos Internacionais de Direitos Econômicos, Sociais e Culturais e de Direitos Civis e Políticos; as recomendações da UNESCO que obrigam os Estados-membros a apresentá-las as autoridades nacionais competentes; a Resolução $n^{0}$ 1803 da AG da ONU, acerca de Soberania Permanente sobre Recursos Naturais; a Convenção Européia, a Convenção Americana e Carta Africana de Direitos Humanos e dos Povos ( Carta de Banjul); o tratado de Roma que confere poderes ao Conselho e a Comissão da Comunidade Econômica Européia; e mais recentemente a aprovação pela Conferência Diplomática das Nações Unidas da Corte Penal Internacional.

O Brasil adotou a Carta Internacional de Direitos Humanos (aprovada por resolução da Onu) de forma a consolidar os direitos fundamentais do homem no art. $5^{\circ}$ e os sociais, no art. $7^{\circ}$.

Finalmente, resta afirmar que os atos dos organismos internacionais constituem fonte do direito internacional, na proporção que todos os Estados aceitam as regras "pacta sunt servanda e consueto sunt servanda", identificando nas resoluções (as decisões e as recomendações) manifestações de vontade desses órgãos, cuja autoridade é reconhecida pelos membros da Comunidade Internacional e expressam o seu consenso geral.

\subsection{ATOS UNILATERAIS DOS ESTADOS}

$\mathrm{O}$ art. 38 da Corte Internacional de Justiça não menciona entre as fontes do direito internacional os atos unilaterais dos Estados.

Para Hee Moon $\mathrm{Jo}^{20}$, os atos unilaterais dos Estados são atos jurídicos referentes à manifestação de vontade do sujeito de direito.

A manifestação de vontade deve ser oriunda de um Estado soberano, cujo objeto seja lícito e não afronte ás normas de direito internacional, a vontade não seja

\footnotetext{
${ }^{20}$ Hee Moon Jo. Introdução ao Direito Internacional. p.144. 
viciada, tem por fim criar uma regra de direito, suprindo a lacuna do sistema jurídico e não solene. Pode ser escrita, oral ou decorrente de silêncio. Em geral não está vinculada ao tratado ou costume internacional, mas pode dele decorrer, naqueles casos excepcionais em que o próprio tratado preveja a sua denúncia ou o seu recesso, nos termos do art. 56 e seguintes Da Convenção sobre o Direito Dos Tratados.

Os atos unilaterais dos Estados podem ser classificados, doutrinariamente, em sete categorias, sejam expressos ou tácitos, solenes ou informais. Adotaremos para efeito do presente trabalho a classificação abaixo:

1. Atos unilaterais expressos ${ }^{21}$ : constituem a maioria dos atos unilaterais praticados. São eles:

- notificação - é ato unilateral do Estado, sujeito ou não a condição futura, por intermédio do qual se leva a conhecimento de outro Estado um fato que tem o condão de produzir ou não efeitos jurídicos, sendo pois apenas declaratória ou constitutiva. São ainda obrigatórias ou facultativas, segundo sejam estabelecidas nos Tratados ou seja faculdade do Estado em querer manifestar-se. Podemos citar como exemplo o art. 65º da Convenção sobre o Direito Dos Tratados, que prevê a notificação como instrumento hábil a fazer cessar a vigência, recesso, suspensão ou nulidade de um tratado, por vício do seu consentimento, ou o art. $16^{\circ}$ que estabelece a notificação como meio necessário para que um Estado expresse o seu consentimento quanto a aceitação, adesão ou ratificação a um tratado. Também é utilizada a notificação nos casos de monitoramento de direitos humanos, quando um Estado-Parte num tratado notifica outro, dado o não cumprimento de suas prescrições perante a Comissão de Direitos Humanos na ONU, sujeitando-o a responder fundamentadamente aos fatos que lhe são imputados. A notificação pode ser revogada antes que produza efeitos, logo a qualquer tempo;

- protesto - instrumento pelo qual o Estado resguarda seus direitos, opondo-se, reiteradamente, à criação de uma nova regra jurídica internacional ou a um ato praticado por outro Estado, que venha a lhe prejudicar ou criar um direito a terceiro. O protesto deve ser revestido dos requisitos comuns a qualquer ato internacional, quais sejam : capacidade do Estado; e em especial do órgão competente para tanto; vontade livre, sem vícios; e objeto lícito e possível. Pode ser dirigido também a terceiro que não o Estado que tenha 
praticado ato que viole os direitos do que protesta. Exemplo clássico é o caso dos protestos dirigidos à ONU, que tem o dever de evitar a violação de direitos, e a manutenção da Paz;

- denúncia - não é posição unânime da doutrina de que esse instrumento constitui-se em ato unilateral, porque tem seu fato gerador nas disposições do tratado. Se ele não a prevê não há como haver denúncia. Todavia três exceções podem se dar. As duas primeiras estão previstas no art. $56^{\circ}$ da Convenção de Viena Sobre Direito dos Tratados, ocorrendo quando os Estados-Partes a admitem expressamente ou quando decorrem da natureza do tratado. A última exceção resulta de um ato de represália do Estado ou de via de fato;

- promessa - não é um instrumento muito utilizado porque se refere a compromissos futuros que são assumidos pelo Estado que a formula em benefício de um outro. Deve o fato objeto da promessa que beneficia o Estado ter sido decorrente de boa-fé, o que motiva a geração de efeitos jurídicos, ficando o Estado formulador da promessa vinculado a seu cumprimento sob pena de sanções. A promessa gera os mesmos efeitos de um acordo celebrado;

- reconhecimento - destaca-se como o principal ato unilateral do Estado, por intermédio do qual uma situação fática ou jurídica é constatada, reconhecida e passa a gerar efeitos. Se opõe ao protesto, porque enquanto neste se quer inviabilizar a criação de uma norma jurídica a partir de um fato, no reconhecimento se pretende o nascimento desta.

Sereni, mencionado por Celso Ribeiro Bastos, no Curso de Direito Internacional Público, p. 293, afirma ser o reconhecimento o ato por meio do qual um sujeito de direito internacional aceita uma determinada situação de fato ou de direito e, eventualmente, declara considerá-la legítima.

Admite-se o reconhecimento tácito quando decorrente de atos inequívocos, sendo oponível seus efeitos a quem o concedeu.

- renúncia - é o ato unilateral do Estado por intermédio do qual há o abandono do direito. Não se confunde com o não exercício, pois deve ser expresso, nunca tácito.

2. Ato unilateral tácito - o silêncio como ato unilateral é equiparado à aceitação, pois o Estado queda-se inerte quanto a manifestação que deveria fazer, quando notificado acerca de seus direitos ou quanto ao seu exercício. Ao tratar da matéria, grande

${ }^{21}$ Rosseau classificou os atos unilaterais em tácito (silêncio) e expressos (protesto, notificação renúncia, 
parte dos doutrinadores menciona que o silêncio de um Estado para que implique em aceitação deverá sser revestido do interesse jurídico do Estado silente no fato, que seja de seu conhecimento prévio e que haja uo decurso de lapso de tempo razoável para que o Estado tenha condições de se manifestar.

Para concluir, é necessário que se realce o art. $2^{\circ}$, alínea b, da Convenção de Viena Sobre Direito dos Tratados dispõe acerca do significado das expressões ratificação, aceitação, aprovação e adesão, como a designação do ato internacional pelo qual um Estado estabelece, no plano internacional, o seu consentimento a ficar vinculado por um tratado; e na alínea d, sobre a expressão reserva, como a declaração unilateral, qualquer que seja o seu conteúdo ou a sua designação, feita por um Estado quando assina, ratifica, aceita ou aprova um tratado ou a ele adere, pelo qual visa excluir ou modificar o efeito jurídico de certas disposições do tratado na sua aplicação a este Estado. Essas duas alíneas mencionadas dizem respeito a atos unilaterais dos Estados que são produzidos em decorrência da negociação de um tratado, valendo lembrar que os atos unilaterais dos Estados, enquanto fontes do Direito Internacional Público, não estão vinculados aos tratados e aos costumes. Ao revés são atos autônomos, daí o questionamento acerca de sua natureza como fontes.

\subsection{JUS COGENS}

A discussão acerca de normas dispositivas e imperativas surge a partir da teoria voluntarista que não admite o surgimento de normas internacionais que não decorram da vontade dos Estados que a elaboram ou a ela aderem.

A denominação iure cogens ou jus cogens surge, primeiramente, no fim do século XVII, no âmbito do direito privado, em relação ao instituto da doação. Entretanto, a pesquisa histórica nos conduz a afirmar que no fim do século XVIII, normas imperativas limitavam o direito das pessoas, estabelecendo restrição ao direito privado e a supremacia das normas cogentes, em geral de natureza pública.

Em âmbito do direito internacional encontramos expressões de normas cogentes em Grotio, no século XVII. Esse conceito é utilizado no século XIX, por Heffter, como normas costumeiras superiores.

reconhecimento e promessa). 
Apesar de previstas na Carta da $\operatorname{LdN}$ e da ONU, o seu conceito e a denominação de jus cogens é adotado formalmente nos arts. $53^{\circ}$ e $64^{\circ}$ da Convenção de Viena sobre o Direito dos tratados, significando a norma imperativa de direito internacional geral que for aceita e reconhecida pela comunidade internacional dos Estados em conjunto como norma à qual nenhuma derrogação é permitida e que só pode ser modificada por uma norma de Direito Internacional geral com a mesma natureza.

As disposições da Convenção acima impõem a nulidade do tratado que seja incompatível, no momento de sua conclusão, com as normas de jus cogens já previstas; ou a nulidade de um tratado preexistente quando sobrevenha uma norma imperativa de direito internacional geral.

Elucidada a questão da denominação e do significado de ius cogens, outra questão relevante é a de se identificar a norma imperativa. Encontramos, em nosso entender, sua primeira expressão no art. $2^{\circ}$ da Carta da ONU que estabelece a igualdade soberana de todos os seus membros; a boa-fé no cumprimento de obrigações assumidas; resolução de controvérsia por meios pacíficos, para que não haja ameaça a mantença da paz e segurança internacionais, bem como da justiça; e por fim a abstenção de recorrer à ameaça e ao uso da força, quer seja contra a integridade territorial ou a independência política de um Estado, quer seja de qualquer outro modo incompatível com os objetivos das Nações Unidas.

Devem ser acrescidas às disposições da Carta da ONU como normas de jus cogens, segundo Juan Antonio Carrilo Salcedo, a obrigação dos Estados cooperarem entre si e a igualdade de direitos e livre determinação dos povos ${ }^{22}$, por força da Resolução ${ }^{\circ}$ 2625 ( XXV).

A norma cogente tem reconhecimento e aceitação pelos membros da sociedade internacional, constituindo-se como fonte do direito, e logo produzindo normas jurídicas internacionais, quando se torna respeitado incondicionalmente (abstenção de recorrer à ameaça e ao uso da força); é objeto de tratados que visem a torná-los efetivos; acarretam a nulidade de tratados internacionais que sejam com ela incompatível ou ainda quando ocorra a supremacia de sua aplicação na resolução de um conflito entre o ius cogens e outra norma de direito internacional. 
As limitações encontradas pelos atos unilaterais dos Estados e das organizações internacionais não atingem o jus cogens como fonte do direito internacional, pois a soberania do Estado não é afetada, pois a norma imperativa é aceita e reconhecida pela comunidade internacional dos Estados em conjunto como norma e não há restrição à sua validade e eficácia eis que nenhuma derrogação é permitida e somente será modificada por uma norma de Direito Internacional geral com a mesma natureza. Nesse diapasão podemos mencionar a proteção dos direitos humanos que deixou de ser matéria pertencente exclusivamente à jurisdição doméstica dos Estados para ser erigida a categoria de jus cogens, conforme afirmação do Instituto de Direito Internacional, que se transcreve abaixo $^{23}$ :

Los derechos humanos son la expresión de la dignidad de la persona humana. La obligacion para los Estados de garantizar que sean respetados se desprende del propio reconocimiento de dicha dignidad, proclamada por la Carta de las Naciones Unidas y la Declaración Universal de Derechos Humanos.

Esta obligación internacional es, égun una fórmula utilizada po la Corte Intenacional de Justicia, uma obligación erga omnes; imcumbe a todo Estado con respecto a la comunidad internacional en su conjunto, y tood Estado está interesado jurídicamente en la protección de los derechos del hombre. Esta obligación implica, ademas, un deber de solidaridad entre toods los Estados,con el fin de garantizar lo más rapidamente posible una protección universal y eficaz de los derechos humanos”.

\section{A EFICÁCIA DAS FONTES NÃO CODIFICADAS NO DIREITO INTERNO E INTERNACIONAL}

O processo de globalização vivenciado pelo mundo, a rapidez com que os fatos sociais vêm ocorrendo e impondo uma regulamentação jurídica célere, o aumento do número de organismos internacionais; a necessidade dos Estados manterem relações diplomáticas e incrementar suas relações comerciais, oferecendo segurança jurídica na celebração de contratos e adquirindo respeitabilidade perante a Comunidade Internacional vêm ocasionando uma diminuição na postergação da aplicação das normas de direito internacional. Tal fato tem sido conseqüência das diversas formas de monitoramento de promoção, tutela e implementação contidas nos estatutos ou documentos constitutivos dos

\footnotetext{
${ }^{22}$ Juan Antonio Carrillo Salcedo. Curso de Derecho Internacional Público - Introdución a su Estrutuctura, Dinámica y Funciones, p.134.

${ }^{23}$ Juan Antonio Carrillo Salcedo. Curso de Derecho Internacional Público - Introdución a su Estrutuctura, Dinámica y Funciones, p.74.
} 
organismos internacionais, quanto a adoção ou não de suas recomendações e do cumprimento de obrigações assumidas pelo Estado, solenemente ou não.

Uma das formas mais usuais de monitoramento dos organismos internacionais é a elaboração de relatórios, onde o Estado explica como está se dando a implementação jurídica e fática das obrigações assumidas no âmbito internacional e se necessita e quer auxílio, evitando que haja a interferência sem autorização do Estado. A grande maioria dos Estatutos dos organismos internacionais já prevêem a forma de controle da aplicação das suas normas, bem como a grande maioria dos tratados e convenções.

Já as controvérsias que ameacem a paz e segurança são resolvidas pelos próprios Estados pode intermédio de soluções pacíficas, como a negociação, o inquérito, a mediação, a conciliação, a arbitragem, via judicial, recursos a organizações ou acordos regionais e ainda, via Conselho de Segurança da ONU, que poderá fazer recomendações as Partes visando resolver pacificamente o conflito. Não sendo o mesmo resolvido poderá ser submetida a controvérsia a Corte internacional de Justiça, por voluntariedade do Estado, que prolatará sentença, com força executória, podendo fazer recomendações ou tomar decisões visando o cumprimento da sentença.

Os atos das organizações internacionais que tem por objeto de estudo e análise os direitos humanos comprova a assertiva de que as fontes não codificadas do direito internacional vêm demonstrando sua eficácia para o controle e o cumprimento das obrigações internacionais pelos Estados, pois os direitos humanos no sistema interamericano começaram por ser protegidos antes mesmo que a Convenção Americana ou Pacto de San José da Costa Rica tivesse existência, pois a Comissão Interamericana de Direitos Humanos surgiu dez antes da Convenção Americana, na V Reunião de Consulta dos Ministros das Relações Exteriores, em Santiago, em 1959, por meio da Resolução VIII.

Inicialmente, a Convenção teve apenas funções de promover os direitos humanos, mas paulatinamente passou a realizar ações voltadas não apenas à promoção, mas efetivamente à tutela, controle e supervisão, o que se concretizou com a Resolução XXII da II Conferência Interamericana Extraordinária, por recomendação da OEA. Somente veio a ganhar natureza jurídica de convenção em 1967, com a modificação da Carta da OEA, e passou então a monitorar o respeito aos direitos humanos, por intermédio do sistema de 
comunicações entre Estados, relatórios e investigações in loco. Foi fator decisivo a sua atuação para o fortalecimento do sistema interamericano de proteção aos direitos humanos.

No campo dos Direitos Humanos as resoluções dos organismos internacionais é indiscutivelmente tratada como fonte do direito internacional e com supremacia de aplicação perante as normas de direito interno. Tanto é assim que a nossa Constituição admite nos seus $\S \S 1^{\circ}$ e $2^{\circ}$, do art. $5^{\circ}$, a aplicação imediata das normas definidoras de direitos e garantias fundamentais, entendendo essas como as constantes na Constituição Federal, decorrentes dos princípios por ela adotados ou dos tratados internacionais em que o Brasil seja parte. O mesmo se pode afirmar quanto à matéria tributária, porque o nosso Código Tributário Nacional estabelece em seu art. $98^{24}$, que os tratados de direito tributário têm supremacia sobre a lei nacional.

Todavia, a aplicação imediata de resoluções de organismos internacionais e dos próprios tratados em outras áreas do direito que não versem sobre direitos humanos e tributário segue procedimento totalmente diverso quanto ao seu reconhecimento e sua aplicação. Deve anteriormente à sua entrada em vigor, ser aprovado pelo Congresso Nacional, por intermédio de Decreto Legislativo e posteriormente ratificado por ato do Presidente da República, nos termos do art. 84, inciso VIII, que estabelece expressamente a competência privativa do Presidente da República para celebrar tratados, convenções e atos internacionais, desde que haja referendo do Congresso Nacional, e do art. 49 , inciso I, que confere ao Congresso Nacional competência exclusiva para resolver definitivamente sobe tratados, acordos ou atos internacionais que acarretem encargos ou compromissos gravosos ao patrimônio nacional.

Finalmente deve-se mencionar como forma de eficácia das fontes não codificadas do direito internacional a Nova Ordem Econômica Internacional que está revolucionando os conceitos tradicionais dos elementos do Estado, que se opera na Comunidade Econômica Européia e em andamento outras formas de blocos econômicos, como o MERCOSUL. 


\section{CONCLUSÃO}

No estudo das fontes do Direito internacional se destacam as fontes não codificas e não convencionais do direito; os atos unilaterais dos Estados, os atos unilaterais dos organismos internacionais e o jus cogens. Todas essas são fontes inquestionavelmente do direito internacional e vêem contribuindo para a reformulação das estruturas dos Estados, do conceito tradicional de sujeito de direito internacional e sobretudo vem ocasionando uma diminuição na postergação da aplicação das normas de direito internacional e até na modificação dos sistemas jurídicos para estabelecer a supremacia dessas sobre a normas de direito interno.

Todavia muitos passos já foram dados no sentido de se reconhecer autoridade aos atos unilaterais dos Estados, aos atos unilaterais dos organismos internacionais e o jus cogens como nascedouro das normas de direito internacional.

Esse reconhecimento decorre dos movimentos de globalização da economia e da absorção pelos Estados de um novo conceito de soberania e de sujeito de direito internacional, de forma a admitir a inserção na ordem interna de normas internacionais de direitos humanos, como a submissão à decisões de Cortes Internacionais de Direitos Humanos, com força executiva; normas trabalhistas da Organização Internacional do Trabalho e mais recentemente a Lei Modelo sobre Comércio Eletrônico elaborada pela Comissão das Nações Unidas para o Direito Comercial Internacional (UNCITRAL); a Convenção Climática de Kioto; e a Conferência das Nações Unidas contra o Racismo, a Discriminação Racial, a Xenofobia e a Intolerância, conhecida como Conferência de Durban.

A aplicação imediata de resoluções de organismos internacionais e dos próprios tratados em outras áreas do direito que não versem sobre direitos humanos e tributário deve seguir o procedimento para a sua inserção na ordem interna, Deve anteriormente à sua entrada em vigor, ser aprovado pelo Congresso Nacional, por intermédio de Decreto Legislativo e posteriormente ratificado por ato do Presidente da República, nos termos do art. 84, inciso VIII, e do art. 49 , inciso I da Constituição Federal Brasileira.

\footnotetext{
${ }^{24}$ O art. 98 do Código Tributário Nacional dispõe: “ Os tratados e as convenções internacionais revogam ou modificam a legislação tributária interna, e serão observados pela que lhes sobrevenha.”
} 
Logo, com a estrutura constitucional em vigor, ainda que o Brasil reconheça as fontes do direito internacional não codificadas, se essas não forem, por intermédio de tratados, convalidados pelos Poderes Legislativo e Executivo, não terão força cogente e logo poder de coerção, de se fazerem valer. Constitui a nossa Lei maior, nesse especial aspecto, um documento anacrônico, pois a legislação de países latino-americanos já prevê a supremacia dos tratados ante à ordem interna.

\section{REFERÊNCIAS}

AgOstinHO, Santo. Confissões. Trad. J. Oliveira Santos e A. Abrósio de Pina, S.J. Nova Cultural. Os Pensadores. São Paulo. 2000.

AKEHUSRST, Michael. Introdução ao Direito Internacional. Coimbra. Livraria Almedina. 1985.

SORENSEN. Max . Manual de Derecho Internacional Público. México. Editado por Max Sorensen. Fondo de Cultura Econômica. 2000.

BASTOS, Celso Ribeiro. Curso de Direito de Direito Internacional Público, São Paulo: Saraiva, $2^{a}$ ed.,2000.

BOBBIO, Norberto. A Era dos Direitos. Trad. De Carlos Nelson Coutinho. São Paulo. Ed. Campus, 1992.

Ed. Campus, 1992. . Positivismo Jurídico Trad. De Carlos Nelson Coutinho. São Paulo.

BOSON, Gerson de Britto Mello. Direito Internacional Público - O Estado em Direito das Gentes. Belo Horizonte. Del Rey. 1994.

Carta da Organização das Nações Unidas-ONU, versão oficial portuguesa, publicada no Diário da República, I Série, de 22 de maio de 1991.

CAMPANHOLE, Hilton Lobo. Constituição do Brasil. São Paulo. Editora Atlas, 14 a Ed., 2000.

CANOTILHO, Joaquim José Gomes. Direito Constitucional e Teoria da Constituição. Coimbra: Almedina, 1998. 
CONSTITUIÇÃO DA REPÚBLICA FEDERATIVA DO BRASIL, São Paulo. Coleção Saraiva de Legislação. Editora Saraiva. 1998.

CONSTITUIÇÃO FEDERAL DE 1988 - 10 anos (1988/1998) - Editora Juarez de Oliveira.

FABRIS, Sergio Antonio. La ONU y la Exégesis de los Derechos Humanos (uma discusión de la nocion). Porto Alegre-RS. Editor Fernando Quintana. 2a Ed. 1999.

JO, Hee Moon. Introdução ao Direito Internacional.São Paulo. LTR. 2000.

LAFER, Celso. A Reconstrução de Direitos Humanos - Um diálogo com o pensamento de Hannah Arendt. São Paulo. Cia. Das Letras. $3^{\text {a }}$ Ed. 1998.

LINDGREN ALVES, José Augusto. Os Direitos Humanos como Tema Global. São Paulo. 1994.

LEWANDOWSKI, Enrique Ricardo. Proteção dos Direitos Humanos na Ordem Interna e Internacional. Rio de Janeiro: Forense, 1984.

LTR-São Paulo. Legislação sobre Direitos Humanos. Compilação Organizada. 1999.

SALCEDO, Juan Antonio Carrillo. Curso de Derecho Internacional Público - Introdución a su Estrutuctura, Dinámica y Funciones. Madrid - España. Editorial Tecnos S.A. 1996.

SEITENFUS, Ricardo e VENTURA, Deisy. Introdução do Direito Internacional Público. Porto Alegre. Livraria do Advogado. 1999.

SILVA, G. E. do Nascimento e - Acciolly, Hildebrando. Manual de Direito Internacional Público. São Paulo. Saraiva. 1998. 